\title{
Assessment Methods Revolution of Landscape Architecture Course Purposed on Cultivation of Comprehensive Qualities
}

\author{
YU Jia \\ Life Science and Engineering College \\ Shen Yang University \\ Liao Ning Province, Shen Yang, 110044
}

\begin{abstract}
Landscape architecture course is an import curriculum in landscape major. Combined the distinguished practicality feature, this paper conducted the assessment methods revolution in the teaching process. The course assessment quota system is established. It stimulated the positivity and creation of students while studying and upgraded the teaching effectiveness.
\end{abstract}

Keywords-landscape architecture; assessment revolution; assessment quota;assessment method

\section{INTRODUCTION}

Landscape architecture, mountain, water and plants are four elements in traditional Chinese landscape gardening. $<$ Landscape Architecture $>$ course is compulsory in landscape major and other relative majors. It has significant functions in cultivating professional quality [1]. The teaching requirement of $<$ Landscape Architecture $>$ course is to make students know the architecture concepts and fundamental knowledge of structure composition by studying and teaching. Students should also get to know the types and layout of Chinese classic landscape architecture, and master in the designing methods and theories for landscape architecture through this course. Cultivating the designing abilities for single building unit in small-scale landscape is required, too.

As long as the speedy development of technology and education, cultivation targets, teaching contents, teaching aids and teaching methods for advanced education ought to be at the same pace of the need of social economy development under the new trend. As the terminal guide of a serial education, the assessment mode plays a significant role. A scientific and standard teaching and education management system is the premise and key point of upgrading the teaching quality and assuring smooth conduction of teaching management. Marks assessment, which is a vital important part of teaching procedure, is the main approach to encourage students to study, grade students, conduct teaching evaluation and gain feedback of teaching [3].

\section{DRAWBACKS OF THE CURRENT ASSESSMENT METHODS}

The assessment method of <Landscape Architecture> course plays a significant role in advanced optimization of $<$ Landscape Architecture $>$ course. Normally, the $<$ Landscape Architecture $>$ course assessment is obtained from the designing assignments. According to the cultivation targets and years of teaching experience, this assessment method has drawbacks.

\section{LESS CORRESPONDENCE TO THE TEACHING PROCEDURES}

$<$ Landscape Architecture $>$ course includes fundamental architecture designing theories,fundamental landscape architecture designing principles and common kinds of landscape architecture designing methods and some other theoretical content and corresponding course designing. All the teaching contents are closely linked. The assessment, which results in a certain lost, fails in reflecting every teaching procedure and cannot tell the studying situation of students thoroughly.

\section{FOCUS ON CONSEQUENCE BUT PROCESS}

The assessment of courses should refer all the import content in the curriculum. It tells the teaching situation via the assessment marks of the students easily. It benefits teachers to propose referring adjustment plans for courses to increase the teaching quality. The practical assessment method cannot reflect students' performance and acceptation of the teaching content during the whole teaching session. This kind of assessment drove students to neglect many parts in teaching process. What's more, the original teaching targets don't come true either.

Part Three Planning of Assessment Quotas and Method Revolution for $<$ Landscape Architecture $>$ Course.

\section{PLANNING OF ASSESSMENT QUOTAS}

First, the former assessment, which focused on teaching and assessing theoretical knowledge but ignored the cultivation of analyzing problems in reality by applying the theoretical knowledge, ought to be changed. Next, the emphasis of the assessment should be transferred from the knowledge system assessment to synthetic quality assessment of students. Then students' schoolwork evaluation quota system is established. Finally, the rational mark structure pattern is composed [4]. Therefore, the assessment has to be objective and fair. According to the content and practical situation of landscape architecture course, the assessment quotas have to be supplemented and refined based on the previous research so that it can reflect students' studying 
situation thoroughly and objectively. Planning of the specific assessment quotas are shown in the following flow chart.

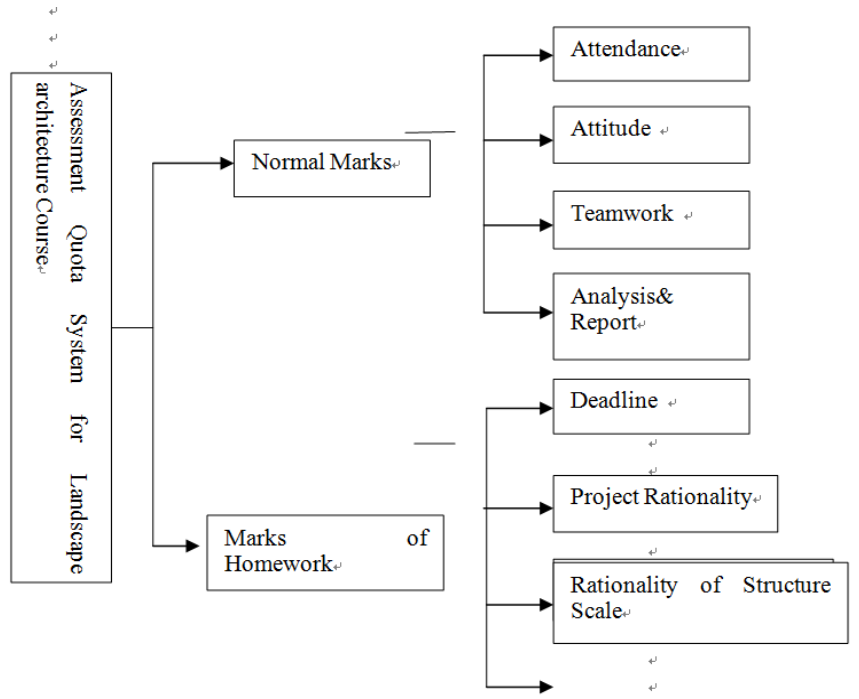

FIGURE I. ASSESSMENT QUOTA SYSTEM FOR <LANDSCAPE ARCHITECTURE $>$ COURSE.

Mark Assessment Revolution for $<$ Landscape Architecture $>$ Course.

\section{NORMAL MARKS}

Full marks were 100 which consisted of attendance (20'), attitude (30'), teamwork (25') and analysis \& report ability (25'). Attendance and analysis \& report ability were assessed during the course session by the teachers. This item had no marks if there was no content related to the analysis \& report. Attitude to the field work and teamwork were the weighted average of self and others assessment values. The group leader got 0.6 as the weights and the group members got 0.4 . In order to keep the agreement of different groups' marks in the whole class, every group's marks were normalized [5]. The average marks took $40 \%$ of the sum.

$$
M_{\text {Attitude }}=\frac{\sum x c i \times p i}{\sum p i} / X C \max \times 30(1)
$$

In formula(1), M Attitude stands for student m's marks for studying attitude; XC stands for studying attitude assessment made by student I; Pi stands for weights 0.4; XCmax stands for the highest marks got from the weighed average of this group;

$$
\mathrm{M}_{\text {Teamwork }}=\frac{\sum \mathrm{Tci} \times \mathrm{pi}}{\sum \mathrm{pi}} / \mathrm{XCmax} \times 25(2)
$$

In formula (2) , M Teamwork stands for the marks of teamwork student $\mathrm{m}$ got; TC stands for teamwork assessment made by student i; Pi stands for weights 0.4; TCmax stands for the highest marks got from the weighed average of this group.

\section{MARKS OF HOMEWORK}

Full marks were 100 which consisted of deadline (25'), project rationality (35'), rationality of structure scale (25') and performance skills (15). The deadline usually decided by the handover time of the homeworks. Full marks were given to homework on time and no marks for homework beyond time requirement; the project rationality mainly investigated the mastery of architecture designing theories and the depth of the analysis of the project. Mastery of the capabilities and advantages \& disadvantages of common architecture materials, simple structural problems (between bidding and fixed) and the convenience to use of various materials were all inspected in the rationality of structure scale. The professional basic skills were studied by the performance skills.

\section{CONCLUSION}

As an extremely important major curriculum, <Landscape Architecture $>$ course is completing and adjusting its assessment methods and quota according to the student's practical situation. Based on the optimized course system and teaching patter, the new assessment method and quota will spirit students' enthusiasm and studying quality. Meanwhile, the target of cultivating synthetic quality of students will be reached.

\section{REFERENCES}

[1] Tang Shi-bin, Rong Li-yu, Guo Song, etal. Teaching revolution Exploration for Course Landscape Architecture [J]. China Education Innovation Herald, 2013(2),203-203

[2] LI Hong, LIANG Xian-chao.The Teaching Reformating of the Coures Landscape Building[J]. Journal of Jinling Institute of Technology, 2008,24(1):93-95

[3] LIU Chang-fu, ZHAO Gui-ling, A Course Examination Mode of Landscape Architecture Ecology Orineted toward Comprehensive Quality Cultivation[J] .Journal of Shenyang Agricultural University(Social Sciences Editinn),2011-07, 13(4): 464-467.

[4] Wang Yong-mei. Investigation and Thinking of Academic Evaluating Reform in Idelolgocal and political Course-- Case Study of Shenyang University[J]. Journal of Shenyang University (Social Science Edition), 2014(5): 674-676.

[5] JIANG Jin-bao, SUN Wen-bin, YUAN De-bao. Reform of Examinating Method of Practical Teaching for Fundamental of Geodesy [J]. Journal of Survey and Draw Journal,2014(5): 130-132. 